\title{
Keeping abreast of shark bite reconstruction: a case report and brief literature review
}

\author{
Alexander I. Murphy ${ }^{1} \cdot$ Adam S. Levy $^{2} \cdot$ J. Simon Ivey $^{3} \cdot$ Jaco Festekjian $^{2}$ \\ Received: 15 September 2021 / Accepted: 26 October 2021 / Published online: 12 November 2021 \\ (c) The Author(s), under exclusive licence to Springer-Verlag GmbH Germany, part of Springer Nature 2021
}

\begin{abstract}
Shark attack-related injuries (SARIs) are rare but may result in highly complex wounds requiring reconstruction by plastic surgeons. Here, we present an unusual case of SARI of the breast and briefly review literature on reconstructive management of (1) breast injuries from other large animals and (2) SARIs to other parts of the body. Our patient was a 39-year-old woman who experienced massive bilateral breast tissue loss from a shark attack. After primary surgical wound management, including debridement and washout, the patient underwent completion mastectomy with bilateral deep inferior epigastric perforator flap breast reconstruction. Literature review revealed that reports of animal-related injuries to the breast are rare, with ours being the first on SARI to the breast and the only describing major reconstruction of animal-related breast injury. Literature on reconstruction of non-breast SARI wounds is limited to two case reports describing severe tissue damage akin to that seen in our patient, both necessitating extensive debridement followed by reconstruction. Overall, our findings demonstrate the uniquely devastating damage resulting from SARIs and the value of primary wound management and abdominally based free flaps in successfully reconstructing these wounds.

Level of evidence: Level V, therapeutic study.
\end{abstract}

Keywords Breast reconstruction · DIEP flap $\cdot$ Shark attack $\cdot$ Shark bite

\section{Introduction}

Shark attacks are rare [1] but may result in devastating tissue loss [2-5]. Improved survival rates after shark attack [6] means more victims may present to plastic surgeons for reconstruction of their shark attack-related injuries (SARIs). SARIs most commonly affect the limbs (60.2\% of cases), although SARIs to the torso $(7.4 \%)$ have been hypothesized as among the more difficult to manage [6]. Here, we describe a unique case of SARI involving the breasts and provide a brief review of literature on reconstruction of (1) animalrelated injuries to the breast and (2) SARIs to other parts of the body.

Alexander I. Murphy

Amrph17@gmail.com

1 Vagelos College of Physicians and Surgeons, Columbia University, New York, NY, USA

2 Division of Plastic Surgery, Department of Surgery, David Geffen School of Medicine/University of California, Los Angeles, Los Angeles, CA, USA

3 Hawaii Permanente Medical Group, Wailuku, HI, USA

\section{Case report}

A 39-year-old woman without past medical history was snorkeling in Hawaii when she was attacked by a large shark. Punching the shark, the patient freed herself from its grasp and swam to shore, where she was assisted by bystanders and taken by ambulance to a trauma center.

The patient was initially found to be in hypotensive shock from hemorrhage, but stabilized with fluid resuscitation. Trauma survey showed skin and soft tissue loss of both breasts, as well as bite wounds of the forehead, abdomen, and left elbow (Fig. 1). She was taken to the operating room for thorough wound washout and debridement. Her breast injuries underwent vacuum-assisted closure and her other superficial wounds were closed primarily. Her remaining hospital course was uncomplicated, and she was discharged on post-injury day (PID) \#8 and returned home to California.

The patient presented to us on PID\#11 to discuss breast reconstructive options. Breast examination found extensive bilateral skin $(\mathrm{R}: 20 \times 12 \mathrm{~cm}, \mathrm{~L}: 13 \times 20 \mathrm{~cm})$ and parenchyma loss, with greater right-sided parenchyma loss. Both nipple-areolar complexes were also lost. She had sufficient 
Fig. 1 Pre-operative shark attack-related injuries to the $\mathbf{A}$ forehead, $\mathbf{B}$ left elbow, $\mathbf{C}$ anterior torso, and $\mathbf{D}$ breasts

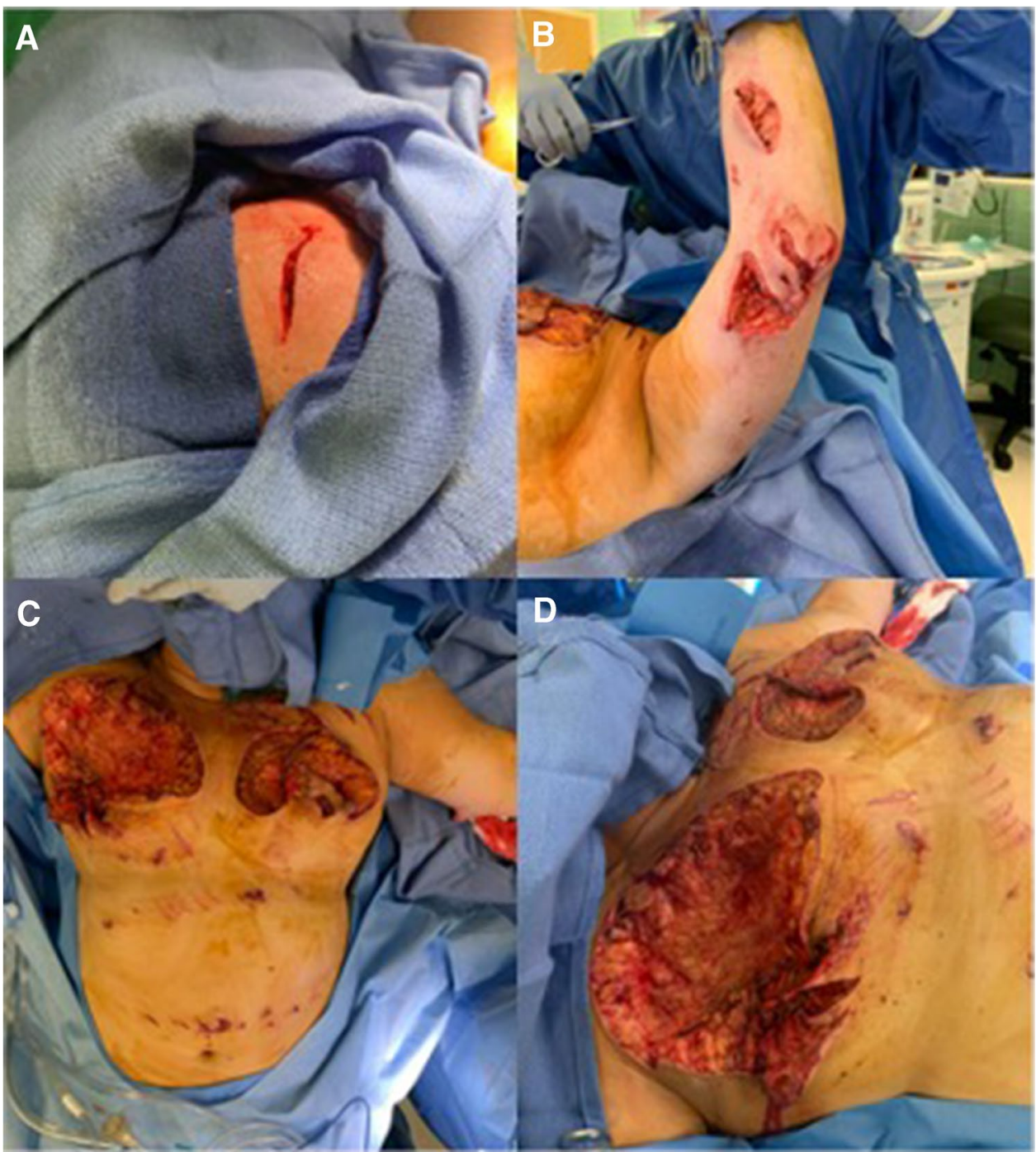

abdominal tissue for breast reconstruction and skin resurfacing so was offered bilateral completion mastectomy and DIEP flap breast reconstruction.

Due to scheduling limitations during the COVID-19 pandemic, reconstruction ultimately occurred on PID\#54. Wound-vacs were removed revealing underlying granulation tissue. Left-sided completion mastectomy was performed while leaving a small amount of superior parenchyma to match the right side. Bilateral DIEP flaps were harvested and anastomosed to internal mammary vessels in standard fashion. Breast mounds were formed and flaps provided adequate coverage for skin defects. She experienced no post-operative complications and was discharged on postoperative day three.

Three months later, the patient returned to us for minor revisions, including nipple reconstruction and abdominal scar revision. On PID\#165, the patient reports good physical health and high satisfaction with her cosmetic outcomes (Fig. 2).

\section{Discussion}

Although still rare, human encounters with sharks are increasing in frequency [6]. To date, literature on treatment of SARIs has primarily focused on initial stabilization, infection control, and primary surgical wound management $[2,7,8]$. With improvement in these techniques, survival rate after SARI has also improved over time [6], meaning a growing number of patients may present to plastic surgeons for definitive SARI reconstruction. In this study, we present a case of management for SARI to the breast, which we successfully reconstructed using DIEP flaps.

Animal-related breast injuries have only been described previously in a handful of case reports and small case studies. A literature review identified articles on injuries from ticks [9, 10], bees [11], spiders [12, 13], scorpions [14], and a leech [15], which had tunneled into the free flap of a 
Fig. 2 Shark attack-related injuries to the breasts reconstructed with DIEP flaps $(\mathbf{A}, \mathbf{B})$

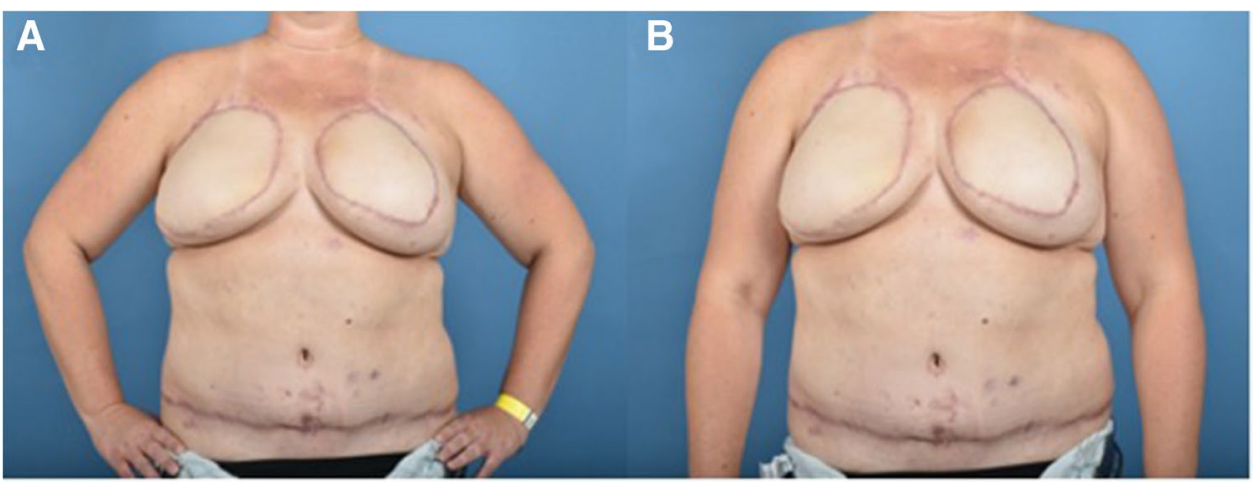

patient undergoing treatment for venous congestion. However, descriptions of reconstructive surgery for animalrelated breast injuries are limited to just two cases. The first report was of a 6-year-old girl who suffered a dog bite to the breast, which was small enough to initially be closed primarily but eventually required minor revision for scarring and nipple flattening [16]. The other patient, an 8-year-old whose breast was bitten by a horse, had an injury that was allowed to heal secondarily but eventually resulted in breast deformity that was corrected with fat grafting [17]. Thus, our patient appears to be both the first case in the literature of SARI to the breast and of animalrelated breast injury requiring major reconstruction.

Sharks are likely one of the few species capable of inflicting the massive tissue damage seen in our patient, and our second review identified two more cases describing reconstruction of SARIs to other body parts. The first described an 18-year-old woman with near-total left thigh loss after shark attack [18]. Her initial wound management included debridement and split-thickness skin grafting, followed 5 weeks later by DIEP flap reconstruction of the thigh. Her course was uncomplicated and, at 1-year follow-up, she experienced only mild limitations to her daily activities. More recently, Roy et al. chronicled the treatment of a 39-year-old woman who presented to them on PID\#6 also suffering from severe SARI to her thigh [19]. On arrival, the patient's leg wound still contained saltwater and sand, and appeared to have been closed with a composite graft of amputated thigh tissue. Cefazolin/metronidazole/clindamycin were initiated for broad coverage, although a recent study identified fluoroquinolones or a third-generation cephalosporin plus doxycycline as better options against shark oral flora [20]. After irrigation and debridement, the patient's wound was first closed on PID\#9 with a free anterolateral thigh flap, which failed on PID\#15. Definitive reconstruction of the thigh was ultimately completed using a free TRAM flap on PID\#393, which reportedly resulted in acceptable cosmetic and functional outcomes.

Comparing our patient to these two other SARI cases yields a few possible implications for future SARI reconstruction. First, the primary wound management period appears important. In the two cases with adequate initial debridement and washout, definitive reconstruction was largely uncomplicated. As with more common penetrating bite wounds, broad-spectrum antibiotic coverage is essential [21, 22]. However, these measures were not applied to the third patient, whose first flap failed and course was much more complicated. Second, our findings suggest that major SARIs may best be repaired with abdominally based free flaps, which were the final reconstructive methods for each case. These flaps are familiar to many plastic surgeons, especially in the setting of oncologic breast reconstruction, and often provide a large volume of both skin and adipose tissue. In many patients, the abdomen may provide the only volume of tissue sufficient for reconstruction of the massive wounds inflicted by sharks.

Author contribution AIM: literature review, manuscript writing and review.

ASL: literature review, manuscript writing and review.

JSI: critical feedback and manuscript review.

JF: study conception, manuscript writing and review.

Data availability All available materials are included in this manuscript.

Code availability No code was used in this manuscript.

\section{Declarations}

Ethics approval All procedures performed in studies involving human participants were in accordance with the ethical standards of the institutional and/or national research committee and with the 1964 Helsinki Declaration and its later amendments or comparable ethical standards. This research is deemed ethics approval-exempt by our institution.

Consent to participate The participant has consented to participate in this study.

Consent to publication The participant has consented for the publication of this study. 
Conflict of interest Alexander I Murphy, Adam S Levy, J Simon Ivey, and Jaco Festekjian declare no conflict of interest.

\section{References}

1. Depart of Land and Natural Resources. Shark safety: close encounters. Published 2021. https://dlnr.hawaii.gov/sharks/sharksafety/close-encounters/. Accessed 8 Apr 2021

2. Caldicott DGE, Mahajani R, Kuhn M (2001) The anatomy of a shark attack: a case report and review of the literature. Injury 32(6):445-453. https://doi.org/10.1016/S0020-1383(01)00041-9

3. Ballas R, Saetta G, Peuchot C, Elkienbaum P, Poinsot E (2017) Clinical features of 27 shark attack cases on La Réunion Island. J Trauma Acute Care Surg 82(5):952-955. https://doi.org/10.1097/ TA.0000000000001399

4. Rtshiladze MA, Andersen SP, Nguyen DQA, Grabs A, Ho K (2011) The 2009 Sydney shark attacks: case series and literature review. ANZ J Surg 81(5):345-351. https://doi.org/10.1111/j. 1445-2197.2010.05640.x

5. Ihama Y, Ninomiya K, Noguchi M, Fuke C, Miyazaki T (2009) Characteristic features of injuries due to shark attacks: a review of 12 cases. Leg Med 11(5):219-225. https://doi.org/10.1016/j.legal med.2009.06.002

6. Ricci JA, Vargas CR, Singhal D, Lee BT (2016) Shark attackrelated injuries: epidemiology and implications for plastic surgeons. J Plast Reconstr Aesthetic Surg 69(1):108-114. https://doi. org/10.1016/j.bjps.2015.08.029

7. Woolgar JD, Cliff G, Nair R, Hafez H, Robbs JV (2001) Shark attack: review of 86 consecutive cases. J Trauma - Inj Infect Crit Care 50(5):887-891. https://doi.org/10.1097/00005373-20010 5000-00019

8. Isci ET, Ritter E (2018) On the complexity of shark bite wounds: from associated bacteria to trauma management and wound repair. J Trauma Acute Care Surg 85(2):398-405. https://doi.org/10. 1097/TA.0000000000001920

9. Colucci R, Galeone M, Arunachalam M et al (2012) Red nodule on the breast. Indian J Dermatol 57(5):397-399. https://doi.org/ 10.4103/0019-5154.100496

10. Dommergaard L, Karlsson LK, Lunding S. Tularaemia in two patients referred on suspicion of cancer mammae and cancer occulta. Ugeskr Laeger. 2020;182(36).

11. Kaya A, Okur M (2012) Bee sting in mother and urticarial rash in her baby. Indian Pediatr 49(6):499. https://doi.org/10.1007/ s13312-012-0065-x
12. Hayes H (1977) Spider bite on augmented breast. Plast Reconstr Surg 59(2):281-282. https://doi.org/10.1097/00006534-19770 2000-00024

13. Norris K, Misra S (2014) Brown recluse spider bite on the breast. J Am Acad Physician Assist 27(5):32-34. https://doi.org/10.1097/ 01.JAA.0000443967.31234.87

14. Moukit M, Kouach J (2020) An unusual site of scorpion bite. Breast J 26(9):1852-1852. https://doi.org/10.1111/tbj.13879

15. Flurry M, Natoli NB, Mesa JM, Moyer KE (2011) Tunneling of a leech into a free flap breast reconstruction. J Plast Reconstr Aesthetic Surg 64(12):1687-1688. https://doi.org/10.1016/j.bjps. 2011.05.014

16. Miyata N, Abe S (1999) Dog-bite injuries to the breast in children: deformities to secondary sex characteristics and their repair in an extended follow-up. Ann Plast Surg 43(5):542-545. https://doi. org/10.1097/00000637-199911000-00014

17. Quoc CH, Meruta A, La Marca S, Fabiano L, Toussoun G, Delay E (2013) Breast amputation correction of a horse bite using the lipomodeling technique. Aesthetic Surg J 33(1):93-96. https://doi. org/10.1177/1090820X12469808

18. Tonkin MA, Lai MF, Kennedy PJ (1987) The extended deep inferior epigastric flap: a case report. Br J Plast Surg 40(5):518-520. https://doi.org/10.1016/S0007-1226(87)90086-5

19. Roy M, Plant MA, Snell L (2018) A shark attack treated in a tertiary care centre: case report and review of the literature. Arch Plast Surg 45(1):80-84. https://doi.org/10.5999/aps.2016.01991

20. Unger NR, Ritter E, Borrego R, Goodman J, Osiyemi OO. Antibiotic susceptibilities of bacteria isolated within the oral flora of Florida blacktip sharks: guidance for empiric antibiotic therapy. PLoS One. 2014;9(8). https://doi.org/10.1371/journal.pone.01045 77

21. Ellis R, Ellis C (2014) Dog and cat bites. Am Fam Physician 90(4):239

22. Stevens DL, Bisno AL, Chambers HF, et al. Practice guidelines for the diagnosis and management of skin and soft tissue infections: 2014 update by the infectious diseases society of America. Clin Infect Dis. Published online 2014. https://doi.org/10.1093/ cid/ciu296

Publisher's note Springer Nature remains neutral with regard to jurisdictional claims in published maps and institutional affiliations. 